\title{
REVIEW ON POST-TREATMENT EMISSION CONTROL TECHNIQUE BY APPLICATION OF DIESEL OXIDATION CATALYSIS AND DIESEL PARTICULATE FILTRATION
}

\author{
Caneon Kurien ${ }^{1, *}$, Ajay Kumar Srivastava ${ }^{1}$
}

\begin{abstract}
The toxic nature of exhaust gases released by these engines has led to environmental concerns, affecting its sustainability. The exhaust emission from diesel engine includes carbon monoxide, nitrates, hydrocarbons and particulate matter. Soot particles contained in the particulate matter is also found to be carcinogenic in nature and also leads to various lung diseases. Diesel oxidation catalysis system involves oxidation of hydrocarbons, nitrates and soluble organic fraction. Diesel particulate filtration blocks the soot particles with the help of alternately plugged diesel particulate filter with porous walls. The regeneration of accumulated soot is one of the major challenges faced by automotive industries for effective implementation of diesel particulate filtration system. A detailed review on the challenges faced in the implementation of emission control techniques has been carried out in this study and it has been explored from the results of literature study that microwave based regeneration technique would be an effective technique. This paper provides a platform for understanding the working principle of post treatment emission control techniques and also on the role of regeneration in effective operation of Diesel Particulate Filter.
\end{abstract}

\section{Keywords: Catalysis, Emission, Oxidation, Soot, Regeneration}

\section{INTRODUCTION}

Diesel engines are considered as second leading anthropogenic source of particulate matter $\left(\mathrm{PM}_{2.5}\right.$ and $\mathrm{PM}_{10}$ ) which is formed due to combustion of fuel and lubricating oil [1]. The exhaust emission from diesel engine includes carbon monoxide, nitrates, hydrocarbons and particulate matter [2]. Particulate matter consists of soluble organic fraction and soot particles. Insoluble organic components of particulate matter have agglomerates in the size range of 0.5 to $5 \mu \mathrm{m}$ while the inorganic non-combustible fraction (ash) will be in a size range of 45 to $160 \mathrm{~nm}$ [3]. Soot particles released from diesel engines are found to be carcinogenic in nature creating a threat to human life [4]. Size and composition of soot particle determines its impact on human health and fine particles with size less than 2.5 $\mu \mathrm{m}$ can reach the alveolar region of human lungs [5]. These emissions can be reduced by two techniques namely pretreatment and post treatment. Exhaust emissions from diesel engine pose a serious threat to environment and human health. Combined application of pre-treatment and post treatment techniques is the only solution to reduce these emissions [6]. Pre-treatment techniques include engine modifications like combustion cylinder alteration, injection timing retard, exhaust gas recirculation, fuel injection strategies and so on [7]. Optimization of fuel injection strategies will have a considerable effect on the reduction efficiency of hydrocarbons in exhaust emissions. Reduction efficiency of the particle oxidation catalyst was calculated for different values of Start of Injection (SOI) and Fuel Injection Pressure (FIP) in [8]. Experimental results showed that higher reduction efficiency is achieved when FIP is in the range of $600-1000$ bar and SOI in the range 0o to 150 crank angle before top dead center (CABTDC). Combustion technology such as homogenous charge compression ignition (HCCI) is found to reduce the emissions without affecting the efficiency of engine [9]. Nitrogen oxide emissions from diesel engines can be controlled by exhaust gas recirculation technology where a certain percentage of exhaust gas is recirculated to intake manifold [10].

Blending of diesel with butanol and pentanol will also reduce the particulate matter emissions to a certain extent [11]. Long chain alcohols will have advantages like higher energy density, cetane number, better miscibility and will be less hygroscopic [12]. Alternative fuels like BTL (Biomass to liquid) and GTL (Gas to liquid) will

This paper was recommended for publication in revised form by Regional Editor Balaram Kundu

Department of Mechanical Engineering, University of Petroleum and Energy Studies, Dehradun, India 248007

${ }^{\star} E$-mail address: ckurien@ddn.upes.ac.in, akumar@ddn.upes.ac.in

Orcid id: 0000-0003-0104-5393, 0000-0003-3439-5269

Manuscript Received 07 March 2018, Accepted 05 April 2018 
decrease the emission of pollutants in terms of nuclei \& accumulation mode particles and also exhibits a similar behavior like diesel [13]. Post treatment techniques involve use of Diesel Oxidation Catalysis (DOC), Diesel Particulate Filter (DPF) and Selective Catalytic Reduction (SCR) [14]. Diesel oxidation catalysis set up consists of a monolith substrate which has wash coat, impeded with thin layer of catalyst and the whole set up is encased in a can. Since Euro 5b norm in 2011, strict regulations have been made for particle number per $\mathrm{km}$ which has forced the manufacturers to incorporate Diesel Particulate Filtration systems in the exhaust line of their vehicles [15].

\section{DIESEL OXIDATION CATALYSIS (DOC)}

DOC filter is used for oxidation of hydrocarbons, nitrates and soluble organic fraction. It is suitably placed before diesel particulate filter since the oxidation of nitrates can be utilized for passive regeneration of the soot in the particulate filter [16]. Precious metals like platinum, palladium and rhodium are used mostly as catalyst. Catalysis can be also performed in two stages, out of which initial stage involves reduction of nitrate emissions using rhodium catalyst. The final stage is the reduction of carbon monoxide and unburned hydrocarbons by oxidizing them over platinum and palladium catalyst [17]. Expensive nature of precious metal catalysts have led to doping of non-noble metals into platinum based catalysts [18]. Huang Jiang et. al 2015, used impregnation method for preparing a series of Platinum-Vanadium/Cerium-Zirconium oxide based diesel oxidation catalysts with different Platinum/Vanadium ratios and the effect of vanadium on Sulphur resistance and catalytic activity was investigated in detail. The results of the tests showed that Platinum-Vanadium/Cerium-Zirconium oxide with only $1 \mathrm{wt} \% \mathrm{Pt}$ catalyst showed the highest catalyst performance with vanadium loading of $1 \mathrm{wt} \%$ [19]. Various reactions taking place inside the DOC filter are shown in equation no (1) - (4).

$$
\begin{aligned}
& 2 \mathrm{NO} \rightarrow \mathrm{N}_{2}+\mathrm{O}_{2} \\
& 2 \mathrm{NO}_{2} \rightarrow \mathrm{N}_{2}+2 \mathrm{O}_{2} \\
& 2 \mathrm{CO}+\mathrm{O}_{2} \rightarrow 2 \mathrm{CO}_{2} \\
& \mathrm{C}_{x} \mathrm{H}_{y}+\frac{(x+y)}{2} \mathrm{O}_{2} \rightarrow x \mathrm{CO}_{2}+\frac{y}{2} \mathrm{H}_{2} \mathrm{O}
\end{aligned}
$$

\section{OXIDATION OF NITRATES FOR $\mathrm{NO}_{2}$ ASSISTED PASSIVE REGENERATION}

In DOC, the oxidation of $\mathrm{NO}$ was found to reduce with time due to formation of Pt oxide. Supply of $\mathrm{H}_{2}$ was proposed to retard $\mathrm{Pt}$ oxide and improve $\mathrm{NO}_{2}$ yield [20]. The effect of $\mathrm{H}_{2}$ was analyzed for 4 gas mixtures and a DOC filter with Pt catalyst and $\mathrm{Al}_{2} \mathrm{O}_{3}$ wash coat was used for evaluation. It was found that for $\mathrm{NO} / \mathrm{O}_{2} / \mathrm{CO} / \mathrm{C}_{3} \mathrm{H}_{6}$ mixtures, $\mathrm{NO}_{2}$ yield was increased when $\mathrm{H}_{2}$ concentration was $250 \mathrm{ppm}$. Also it reduced light off temp for $\mathrm{C}_{3} \mathrm{H}_{6}$ oxidation. There was a temporal enhancement in $\mathrm{NO}_{2}$ yield due to hydrogen supplementation. Concentrations above $250 \mathrm{ppm}$ were found to reduce $\mathrm{NO}_{2}$ yield. The effect of hydrogen on the $\mathrm{NO}$ oxidation was well known but it was not concluded whether it is due to the temperature rise caused by hydrogen oxidation or due to its influence on reaction kinetics [21].

\section{CFD ANALYSIS OF DOC FILTER}

CFD analysis has been very much effective in optimizing the designed systems in virtual environment so that manufacturing of the optimized design model can be done [22]. It is an effective tool for determining the performance characteristics of designed models prior to manufacture of prototype [23]. Three dimensional flow simulations of flow field in a catalytic converter (DOC) were performed in [24]. Simulation of DOC was carried out and chemical reactions involved in it were considered. Monolith was considered as porous medium and the values of parameters are determined at three sections. Validation of design was carried out by flow and pressure drop analysis [25]. Results showed that sudden expansion of diffuser at inlet resulted in recirculation zone which would lead to 
performance downgrade of the converter. Simulation on existing exhaust system design of a light commercial vehicle was carried out in [26].

Designing was done in CATIA V5 and simulation was carried out in CFX tool. Pressure drop in the converter has been determined by simulation. Since it is validation of the design, no chemical reaction and no heat exchange were considered for the simulation. The initial conditions and properties of exhaust gas considered for the simulation were as follows (1) density $=0.5508 \mathrm{~kg} / \mathrm{m}^{3}$ (2) Viscosity $=3.814 \times 10-4$ Pa.s (3) mass flow rate $=320$ $\mathrm{kg} / \mathrm{hr}$ (4) Temperature $=520$ degree C (5) Pressure at inlet $=212 \mathrm{mbar}$. The results of simulation showed that there was a total pressure drop of 184 mbar in the exhaust system consisting of a muffler, underbody catcon and close coupled catcon. Hayes et al, developed various single channel models of the catalytic converter using phoenics software and carried out simulations to determine the effect of changing cell density and wall thickness at constant wash coat loading [27].

\section{DIESEL PARTICULATE FILTRATION (DPF)}

Development of a reliable, fast and cost effective Diesel Particulate Filter (DPF) is one of the major technical challenges faced by Automotive and other industries [28]. DPF is of two types namely flow through filter (made of ceramic foam or wire mesh or metal wool, filtration efficiency $<60 \%$ ) and wall flow type filter (Honeycomb monolith, filtration efficiency $=95 \%$ ) [29]. Emission tests carried out in DPF having open torturous channels instead of alternately plugged channels showed that the particle emissions were higher since the filter was open structured which made it difficult to block particles [30]. Emission tests were carried out on the basis of EURO steady state cycle where the load is increased from $10 \%$ to $100 \%$ of full load at intervals of $10 \%$. High filtration efficiency of wall flow filters has made it a standard requirement for diesel vehicles for meeting the emission norms [31].

\section{HISTORY OF DPF}

The soot removal from the exhaust gas of heavy duty diesel engines by application of particulate traps with metal fiber mesh were started in 1969[32]. Particulate traps with ceramic fiber coil were introduced in 1978 [33]. The system consisted of multiple punched metal tubes wound with ceramic fiber. Diesel oxidation catalyst filter were not used upstream during that time since the sulphur content in fuel was high and it would lead to sulphur poisoning. Regeneration of accumulated soot particles were carried out by injecting various oxidizing agents like copper chloride, copper perchlorate and acetyl acetone. The research on particulate traps ended in 1994 since the emission norms were met by engine alterations. As the emission standards got stringent with time, the particulate traps (Ceramic and Metallic DPF) gained attention since the EURO $5 \mathrm{~b}$ emission norms forced the manufacturers to restrict the particle number emission [34].

Declaration of environmental institutes to for regulation of particulate matter on basis of particle number in addition to mass concentration made DPF standard mandatory after treatment component [35]. Flow through DPF filters with metallic foam was found to remove only $50 \%$ of particulate matter by mass [22]. Metallic wall flow filters decreased the mass concentration by $50-70 \%$ and particle number by $50 \%$. Removal of soot, ash deposits and characteristics of materials used were some of the challenges faced during the development stage of DPF. Availability of low sulphur fuel has also made it possible to place DOC before DPF for enhancing passive regeneration [36].

\section{FILTRATION MECHANISM OF DPF}

Wall flow Diesel Particulate filter consists of alternately plugged channels where the gas enters through open channels in the inlet and finds the other end of these channels closed forcing it to flow through the porous wall and thus particulate matter gets filtrated [37]. Operating principle of DPF is detailed in figure 1. The accumulated soot particles lead to restriction in flow of gas and increase the exhaust backpressure affecting the efficiency of the engine. The accumulated soot particles have to be oxidized periodically for regeneration [38]. The particulate matter emitted by diesel engines consists of particles in accumulation mode (carbonaceous agglomerates) and nucleation mode (volatile organic and inorganic components like sulphates). The filtration in DPF takes place in two stages, 
namely depth filtration and cake filtration. Initially the soot particles will get trapped in the porous wall of the filter which is called as depth filtration. Cake filtration occurs when particle packing density reaches a maximum causing occlusion of pores and the accumulated particulate matter layer acts as a porous medium to filter the upcoming particles in gas [39]. Transition from depth filtration to cake filtration occurs at a pressure drop range of $700 \mathrm{~Pa}$. Filtration of soluble organic fraction is not as effective as soot filtration [30]. Regeneration can be carried out by passive and active regeneration methods [40].

\section{CATALYST BASED PASSIVE REGENERATION OF DPF}

Passive regeneration is a continuous regeneration process by application of fuel borne catalyst and $\mathrm{NO}_{2}$ assisted passive regeneration. Catalyst based regeneration can be carried out by either adding the catalyst to the fuel as organic derivatives or by deposition of catalytic coating to the filter surface. The purpose of the catalyst is to lower the ignition temperature of diesel soot [41]. Fuel borne catalysts will oxidize a part of soot in combustion chamber and will subsequently improve the soot light off in DPF [42]. Most commonly used fuel borne catalysts are cerium or iron or copper based organic compounds but it will be collected in filter as loose ash [43]. Deposition of transition metals (cobalt, copper and iron) doped with ceria oxide catalysts showed good soot oxidation activity and also reduced the ignition temperature of soot from 550 degree Celsius to 180-400 degree Celsius. Investigation on catalytic combustion of soot under CePr active phase was carried out in realistic reaction conditions by [44]. The results showed that ceria based catalysts are capable of accelerating soot combustion under real conditions. Cerium oxide $\left(\mathrm{CeO}_{2}\right)$ based catalytic DPF oxidizes the particulate matter on ash layer up to thickness of about $100 \mu \mathrm{m}$ whereas Platinum/Alumina based DPF promotes oxidation of PM up to ash layer thickness of 50 $\mu \mathrm{m}$ only[45].

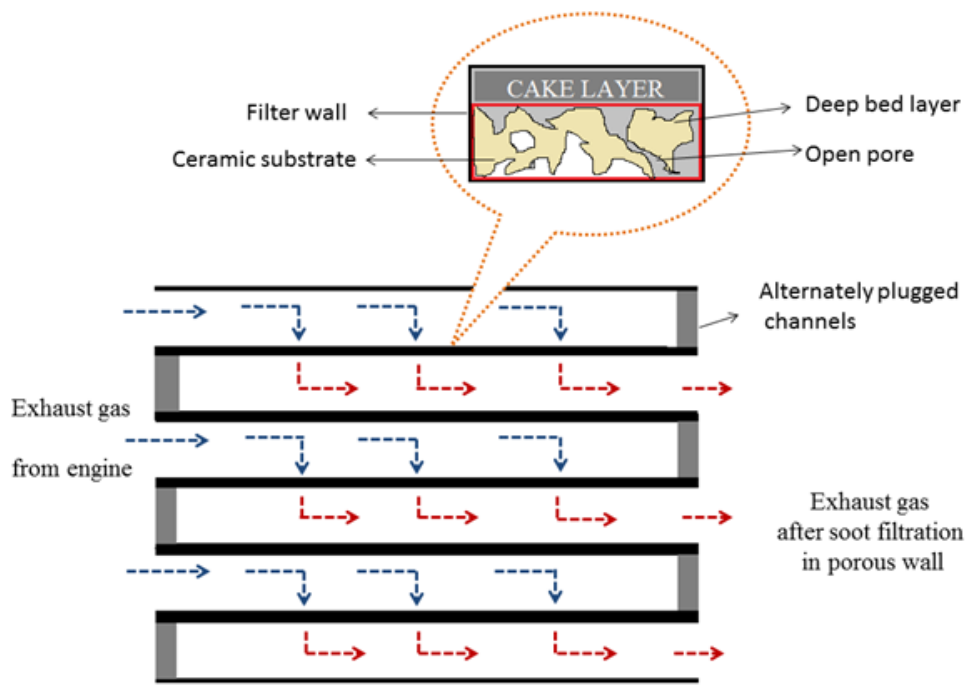

Figure 1. Filtration mechanism of DPF

Copper based catalysts were also found to be a suitable alternative for precious metal catalysts owing to its high catalytic activity, nitrogen oxide reduction and hydrocarbon oxidation [46]. It was found that Copper based catalysts can be used as an efficient alternative catalyst for abatement of particulate matter at low temperatures even at 150 degree Celsius. Palma et. al, developed an optimized preparation procedure for catalytic DPF and also studied the effect of active species load [47]. Catalytic DPF was prepared by repeated impregnation in solution of catalyst (drying at 60 degree Celsius) and calcination at 1000 degree Celsius after each impregnation. Preparation procedure supported the deposition of active species on filter without wash coat. An increase in NOx emissions were found in the downstream of catalytic Pt coated Diesel Particulate Filter [48]. Reason for high NOx emissions from DPF was due to high content of $\mathrm{Pt}$ in coating and low space velocity. Catalytic activity of the $\mathrm{Ag}-\mathrm{K} / \mathrm{CZA}$ with platinum was experimented on the synthetic soot prepared in laboratory conditions and the results showed that the reactivity of 
synthetic soot was lower as compared to real soot [49]. Catalyst load in the filter can be increased by modifying the porosimetric characteristics of the filter material so that the particulate matter oxidation temperature and pressure drop can be maintained at lower levels [50]. Catalyst based regeneration techniques are complex phenomenon because of the complexity of chemical reactions taking place inside the filter and it is a slower process since there will be poor contact between soot and catalyst [51].

\section{$\mathrm{NO}_{2}$ ASSISTED PASSIVE REGENERATION OF DPF}

Post injection and intake throttle valve will have significant impact on exhaust temperature [52]. Engine exhaust temperature is an important factor affecting the NOx emissions and maximum emissions were found at temperature range of 300 to 350 degree Celsius. $\mathrm{NO}_{\mathrm{x}}$ emissions were low when the exhaust gas temperature was below 200 degree Celsius and above 400 degree Celsius. Continuous regeneration technology in DPF involves initial oxidation of soot by $\mathrm{NO}_{2}$ released as a product of reactions taking place inside DOC and further oxidation of soot by reaction with oxygen [43]. DOC is placed upstream of DPF to enhance the $\mathrm{NO}_{2}$ assisted passive regeneration. Mathematical model for $\mathrm{NO}_{2}$ assisted regeneration was developed in [53], where the results showed that the regeneration speed is optimum when the length of filter is in the range $200 \mathrm{~mm}$ to $250 \mathrm{~mm}$ and the channel thickness is below $0.31 \mathrm{~mm}$. The parameters which influence the regeneration speed of DPF in case of $\mathrm{NO}_{2}$ assisted regeneration are as follows; flow rate of exhaust gas, temperature of exhaust gas, concentration of $\mathrm{NO}_{2}$ and mass fraction of $\mathrm{NO}_{2} / \mathrm{PM}[13]$.

\section{COMMERCIAL FUEL BASED ACTIVE REGENERATION OF DPF}

Active regeneration methods include non-thermal plasma techniques, ozone injection, application of induction heating and post fuel injection. Fuel based regeneration method is commercially used for regeneration where a secondary fuel is injected and it burns the accumulated soot particles [54]. Fuel based regeneration affects the durability of DPF and also causes lubricant oil dilution which results in an increase in engine wear and also increases the frequency of maintenance. The burning of the accumulated soot particles creates overheating spots in the filter which will damage the system [55]. A single channel model of the DPF filter was used in [56] for simulating the soot combustion in a DPF. The results of simulation showed that the combustion of soot causes a high temperature rise in the filter which would affect the durability of DPF. Uncontrolled combustion during Fuel based regeneration will result in failure of DPF by formation of cracks, melts and pinholes [1].

Ash formed after regeneration will mix with the soot particles to form a particulate layer causing higher pressure drop. It can be reduced if ash is deposited in the rear part of the inlet channel. A novel technique on pre-DPF water injection was proposed in [57], where the redistribution of accumulated soot particles was carried out by dragging the particles with the help of water to the end of the inlet channel. But it was observed that the injection of water will reduce the temperature at inlet and outlet of the DPF. The temperature at inlet will be recovered instantaneously because of engine operating conditions while the temperature at outlet will take some time to recover due to higher residence time of water. It was also observed that the particle emissions increased during water residence in DPF.

\section{OTHER TECHNIQUES FOR ACTIVE REGENERATION OF DPF}

Application of electric heaters for regeneration of trapped soot particles were studied in [58]. A semi analytical model for analysis of filter behavior during soot loading and regeneration was developed in [59]. Oxidation of soot by application of Non thermal plasma technique was also proposed in [60]. Diesel exhaust gas is passed through a catalyst bed of metal oxides and corona plasma reactor where plasma charge is direct to exhaust gas and catalysts. Catalyst reacts with plasma charge $\left(\mathrm{O}_{3}\right)$ to give $\mathrm{O}$ and $\mathrm{O}_{2}$. $\mathrm{O}$ is very much reactive and it oxidizes the soot. Oxidation of soot depends on ability of catalyst to absorb $\mathrm{O}_{2}$ and supply O. Tuler et al, developed a simple DPF system with a honeycomb monolith (70\% sepiolite and 30\% Silicon carbide) and active species. Catalytic ingredients like cobalt, cerium, barium, potassium etc. were used to decrease the temperature of soot combustion. It was found that the monolith with $70 \%$ natural clay in its composition had similar characteristics to commercially available DPF monoliths. The pore size of the monolith has to be improved for better filtration efficiency [61]. 
A combination of flow through DPF and electrostatic filtration system for improving the filtration efficiency was developed in [62], by placing corona chargers upstream of DPF. Corona discharge was placed perpendicular to the direction of exhaust flow. It was found that the filtration efficiency of the flow through filter improved from 20$40 \%$ to $40-95 \%$, but corona discharge became unstable when the load and speed were increased. A system for regeneration of soot by discharging a capacitor into filter was developed by Graupner et al, where the accumulated soot particles were removed by formation of shock in the surrounding air [63]. The regeneration took place in three stages where first one involves the application of high voltage pulse to the filter to initiate resistive current flow, second stage is the occurrence of micro discharge to erode the soot layer and the final stage involves underdamped LC oscillations by elements. The cake layer in the filter walls were removed completely but it was found that the third stage of regeneration is leading to formation of pinholes and ringing in the substrate.

\section{MICROWAVE ASSISTED ACTIVE REGENERATION OF DPF}

Microwave energy is considered as the best alternative for regeneration of DPF because of its ability to penetrate instantaneously into the filter without heating the exhaust gases [64]. Microwave radiations also enhance rapid and uniform heating of the filter by resistance heating. Microwave based regeneration will reduce the energy consumption by replacing secondary fuel injection and it is independent of the engine operating conditions [65]. Properties of microwave which makes it suitable for regeneration purpose includes instantaneous penetration into filter body, selective absorption of microwave by soot layer and good dielectric property of the filter material [66]. The material of the particulate filter must have good permeability (like ceramic, silicon carbide etc.) which will allow the microwaves to pass through it without heating the exhaust gases. The dielectric properties of a material determine its ability to get heated by microwaves [67]. The dielectric constraints consist of real and imaginary components as shown in equation number 5 .

$$
\varepsilon^{\prime}+j \varepsilon^{\prime \prime}=\varepsilon
$$

When the trapped soot particles are subjected to microwave radiations, it gets heated up directly by the microwaves while the cordierite material will get heated up only by conduction or by convection of heat from soot. The values of dielectric constant for different materials are given in table no. 1. Microwave radiations heat the soot particles by interaction between high frequency electromagnetic field and soot. Design of oven cavity, where the microwave radiations are introduced by magnetron must be done by considering the parameters like dimensions, resonant properties of oven cavity and energy density in cavity [68]. Oven cavity should have good heating pattern and also should present proper load to magnetron. A design model of microwave based regeneration system is developed as shown in figure 2 .

Table 1. Dielectric properties of materials [64]

\begin{tabular}{|c|c|c|}
\hline Material & Dielectric constant $\left.\mathbf{(}^{\prime}\right)$ & Dielectric loss factor $\left(\boldsymbol{\varepsilon}^{\prime \prime}\right)$ \\
\hline Diesel soot & 10.70 & 3.60 \\
\hline Cordierite & 2.90 & 0.140 \\
\hline Alumina ceramic & 8.90 & 0.009 \\
\hline Quartz & 3.80 & 0.0001 \\
\hline
\end{tabular}

Microwave radiations produced by Vector Network Analyzers (VNA) were used by Feulner et al, for determining the soot loading in the DPF [69]. Electromagnetic filed is impressed to the filter housing which acts as resonator through one or two ports. Electric and magnetic field is induced inside the resonator depending the frequency and properties of material inside the filter housing. The amount of soot loaded in the filter can be determined by the value of transmission factor measured at ports. 


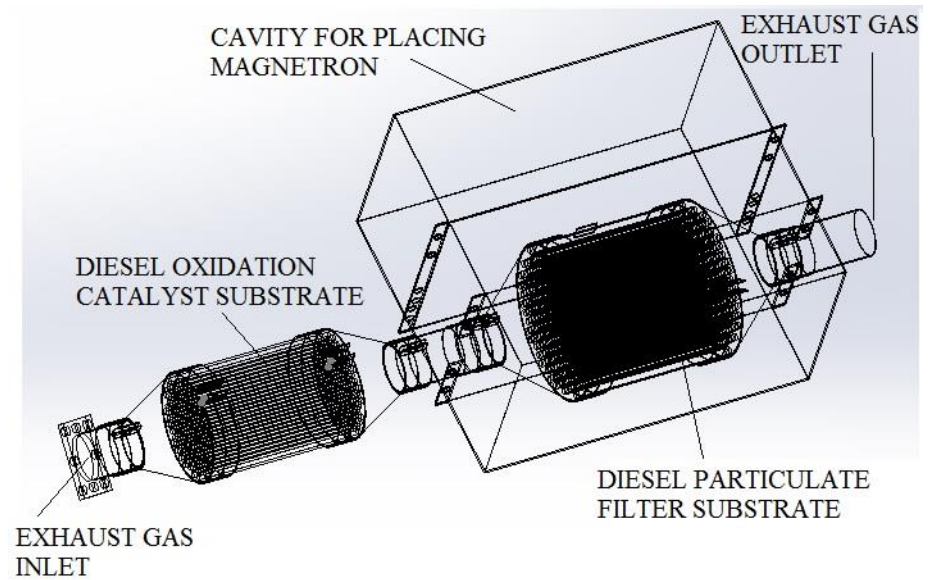

Figure 2. Design model of microwave based regeneration system

\section{COMPOSITE REGENERATION OF DPF}

Composite regeneration is the combination of active and passive regeneration technique where catalyst based regeneration (either by mixing in fuel or by deposition on filter substrate) and thermal based regeneration (post fuel injection, microwave based, heaters etc.) is used simultaneously. In DPF there is a mutual contradiction between filtration efficiency and pressure drop. Multidisciplinary optimization models are used for systems whose performances could conflict with each other.

A multidisciplinary optimization model for composite regeneration was developed in [70], with pressure drop, regeneration performance, microwave energy consumption and thermal shock resistance as its objective functions. Zuo et al, developed a three dimensional model of particulate filter to evaluate the performance of composite regeneration by coupling cerium based catalyst and microwave radiations using multi-field synergy principle [70]. Microwave radiations will enter the filter in the form of travelling waveguide and burns the trapped soot particles. Development of an alternative regeneration technique using electromagnetic waves in microwave region is the only possible solution for improving the durability of DPF and also for meeting the emission norms.

\section{CONCLUSION}

Diesel engines have become an integral part of automotive and other industries because of its higher thermal efficiency. The emission norms by various environmental protection agencies have become stringent in order to reduce these emissions to acceptable limits. The review of emission control system technique using diesel oxidation catalysis and diesel particulate filtration has brought us substantial information about its working principle and also on the major research challenges faced by these techniques. Fuel based traditional regeneration of Diesel Particulate Filter is leading uncontrolled combustion inside the filter substrate affecting the durability of filter substrate. Development of an innovative alternate regeneration system for effective operation of particulate filter is the major technical challenge. Results of the alternate regeneration techniques by application of electric heaters, corona discharge, pulsed discharge etc. failed to improve the durability of filter

Application of microwave energy for regeneration of DPF is considered as possible alternative. Microwave radiations can penetrate into the filter instantaneously to burn the deposited particles by selective absorption owing to its good dielectric properties. It has been concluded from the literature study that the emission control systems play an important role in the roadmap to reduce carbon emissions. Various challenges faced by diesel particulate filtration system have been addressed and an effective system with alternate regeneration technique with application of microwave energy has been proposed. The exhaust emissions can be brought down to acceptable levels by composite regeneration technique involving microwave energy and fuel additives. Future scope of this study includes the development of the proposed system with composite regeneration technique. 


\section{ACKNOWLEDGEMENTS}

The research work performed in this paper is funded and supported by internal seed fund project grant by $\mathrm{R}$ \& D department, UPES. The authors also thank Department of Mechanical Engineering, UPES for their extended help and support.

$\begin{array}{ll}\text { NOMENCLATURE } \\ C F D & \text { Computational Fluid Dynamics } \\ \mathrm{CZA} & \text { Oxides of Cerium, Zirconium and Aluminium } \\ \mathrm{CO} & \text { Carbon monoxide } \\ \mathrm{CO}_{2} & \text { Carbon dioxide } \\ \mathrm{C}_{x} \mathrm{H}_{y} & \text { Hydrocarbon } \\ \mathrm{DOC} & \text { Diesel Oxidation Catalysis } \\ \mathrm{DPF} & \text { Diesel Particulate Filter } \\ F I P & \text { Fuel Injection Pressure } \\ \mathrm{NO} & \text { Nitric Oxide } \\ \mathrm{NO}_{2} & \text { Nitrogen dioxide } \\ \mathrm{N}_{2} & \text { Nitrogen } \\ \mathrm{O}_{2} & \text { Oxygen } \\ \varepsilon^{\prime} & \text { Dielectric constant } \\ \varepsilon^{\prime \prime} & \text { Dielectric loss factor }\end{array}$

\section{REFERENCES}

[1] Yang, K., Fox, J. T., \& Hunsicker, R. (2016). Characterizing diesel particulate filter failure during commercial fleet use due to pinholes, melting, cracking, and fouling. Emission Control Science and Technology, 2(3), 145-155.

[2] Shankar, S., Astagi, H. V., Hotti, S. R., Hebbal, O., Dixit, M., Kaushik, S. C., ..\& Sharifishourabi, M. (2016). Effect of Exhaust Gas Recirculation (EGR) on Performance, Emissions and Combustion Characteristics of a Low Heat Rejection (LHR) Diesel Engine Using Pongamia Biodiesel. Journal Of Thermal Engineering, 2(6), 1007-1016. [3] Liati, A., Schreiber, D., Dimopoulos Eggenschwiler, P., \& Arroyo Rojas Dasilva, Y. (2013). Metal particle emissions in the exhaust stream of diesel engines: an electron microscope study. Environmental science \& technology, 47(24), 14495-14501.

[4] McClellan, R. O., Hesterberg, T. W., \& Wall, J. C. (2012). Evaluation of carcinogenic hazard of diesel engine exhaust needs to consider revolutionary changes in diesel technology. Regulatory Toxicology and Pharmacology, 63(2), 225-258.

[5] C. Kurien and A. K. Srivastava (2017), "Investigation on power aspects in impressed current cathodic protection system," Journal of Corrosion Science and Engineering, vol. 20.

[6] Porpatham, E., Ramesh, A., \& Nagalingam, B. (2007). Effect of hydrogen addition on the performance of a biogas fuelled spark ignition engine. International Journal of Hydrogen Energy, 32(12), 2057-2065.

[7] Sindhu, R., Rao, G. A. P., \& Murthy, K. M. (2017). Effective reduction of NOx emissions from diesel engine using split injections. Alexandria Engineering Journal.

[8] Guan, C., Li, X., Liao, B., \& Huang, Z. (2016). Effects of fuel injection strategies on emissions characteristics of a diesel engine equipped with a particle oxidation catalyst (POC). Journal of Environmental Chemical Engineering, 4(4), 4822-4829.

[9] Pandey, S., Diwan, P., Sahoo, P. K., \& Thipse, S. S. (2018). A review of combustion control strategies in diesel HCCI engines. Biofuels, 9(1), 61-74.

[10] Chintala, V., Kumar, S., \& Pandey, J. K. (2018). A technical review on waste heat recovery from compression ignition engines using organic Rankine cycle. Renewable and Sustainable Energy Reviews, 81, 493-509.

[11] Hotti, S., \& Hebbal, O. (2015). Biodiesel production and fuel properties from non-edible Champaca (Michelia champaca) seed oil for use in diesel engine. Journal of Thermal Engineering, 1(1), 330-336.

[12] Zhang, Z. H., Chua, S. M., \& Balasubramanian, R. (2016). Comparative evaluation of the effect of butanoldiesel and pentanol-diesel blends on carbonaceous particulate composition and particle number emissions from a diesel engine. Fuel, 176, 40-47. 
[13] Wang, D., Liu, Z. C., Tian, J., Liu, J. W., \& Zhang, J. R. (2012). Investigation of particle emission characteristics from a diesel engine with a diesel particulate filter for alternative fuels. International Journal of Automotive Technology, 13(7), 1023-1032.

[14] Caliskan, H., \& Mori, K. (2017). Environmental, enviroeconomic and enhanced thermodynamic analyses of a diesel engine with diesel oxidation catalyst (DOC) and diesel particulate filter (DPF) after treatment systems. Energy, $128,128-144$.

[15] Kurien C., Srivastava A.K. (2018) Active Regeneration of Diesel Particulate Filter Using Microwave Energy for Exhaust Emission Control. In: Singh R., Choudhury S., Gehlot A. (eds) Intelligent Communication, Control and Devices. Advances in Intelligent Systems and Computing, vol 624. Springer, Singapore.

[16] Carrillo, C., DeLaRiva, A., Xiong, H., Peterson, E. J., Spilde, M. N., Kunwar, D., ... \& Challa, S. R. (2017). Regenerative trapping: How Pd improves the durability of Pt diesel oxidation catalysts. Applied Catalysis B: Environmental, 218, 581-590.

[17] Taibani, A. Z., \& Kalamkar, V. (2012). Experimental and computational analysis of behavior of three-way catalytic converter under axial and radial flow conditions. International Journal of Fluid Machinery and Systems, 5(3), 134-142.

[18] Zheng, M., \& Banerjee, S. (2009). Diesel oxidation catalyst and particulate filter modeling in active-flow configurations. Applied Thermal Engineering, 29(14-15), 3021-3035.

[19] Huang, H., Jiang, B., Gu, L., Qi, Z., \& Lu, H. (2015). Promoting effect of vanadium on catalytic activity of $\mathrm{Pt} / \mathrm{Ce}-\mathrm{Zr}-\mathrm{O}$ diesel oxidation catalysts. Journal of Environmental Sciences, 33, 135-142.

[20] Azis, M. M., Auvray, X., Olsson, L., \& Creaser, D. (2015). Evaluation of H2 effect on NO oxidation over a diesel oxidation catalyst. Applied Catalysis B: Environmental, 179, 542-550.

[21] Jiao, P., Li, Z., Shen, B., Zhang, W., Kong, X., \& Jiang, R. (2017). Research of DPF regeneration with NOx-PM coupled chemical reaction. Applied Thermal Engineering, 110, 737-745.

[22] Yoon, C. S., \& Cho, G. B. (2009). Study of Design \& CFD Analysis for Partial DPF Utilizing Metal Foam. Transactions of the Korean Society of Automotive Engineers, 17(1), 24-34.

[23] K. Abay and U. Colak (2018), "Computational Fluid Dynamics Analysis of Flow and Combustion," Journal of Thermal Engineering, vol. 4, no. 2, pp 1878-1895.

[24] Fornarelli, F., Camporeale, S., Dadduzio, R., Fortunato, B., \& Torresi, M. (2015). Numerical simulation of the flow field and chemical reactions within a NSC diesel catalyst. Energy Procedia, 82, 381-388.

[25] D. Khan and Z. Gul (2017), "Performance Map Measurement, Zero-Dimensional Modelling \& Vibration Analysis of A Single Cylinder Diesel Engine," Journal of Thermal Engineering, vol. 3, no. 4, pp. 1391-1410, 2017.

[26] Arthanareeswaren, G., \& Varadarajan, K. N. (2015). CFD study on pressure drop and uniformity index of three cylinder LCV exhaust system. Procedia Engineering, 127, 1211-1218.

[28] Lee, G. W., Yoon, K., Chun, B., \& Jung, H. W. (2018). Lattice Boltzmann simulations for wall-flow dynamics in porous ceramic diesel particulate filters. Applied Surface Science, 429, 72-80.

[29] Lapuerta, M., Rodríguez-Fernández, J., \& Oliva, F. (2012). Effect of soot accumulation in a diesel particle filter on the combustion process and gaseous emissions. Energy, 47(1), 543-552.

[30] Feng, X., Ge, Y., Ma, C., Tan, J., Yu, L., Li, J., \& Wang, X. (2014). Experimental study on the nitrogen dioxide and particulate matter emissions from diesel engine retrofitted with particulate oxidation catalyst. Science of the Total Environment, 472, 56-62.

[31] Louis, C., Liu, Y., Martinet, S., D'Anna, B., Valiente, A. M., Boreave \& André, M. (2017). Dilution effects on ultrafine particle emissions from Euro 5 and Euro 6 diesel and gasoline vehicles. Atmospheric Environment, 169, 8088.

[32] Dittler, A. (2017). The Application of Diesel Particle Filters-From Past to Present and Beyond. Topics in Catalysis, 60(3-5), 342-347.

[33] H. Hardenberg (1987), "Urban Bus Application of a Ceramic Fiber Coil Particulate Trap," SAE Technical Paper, no. 870011 , p. 12.

[34] D. H. and E. H. Hardenberg H (1987), "Particulate Trap Regeneration Induced by Means of Oxidizing Agents injected Into the Exhaust Gas," SAE Technical Paper, no. 870016, p. 16.

[35] Suarez-Bertoa, R., \& Astorga, C. (2018). Impact of cold temperature on Euro 6 passenger car emissions. Environmental Pollution, 234, 318-329.

[36] Millo, F., Rafigh, M., Andreata, M., Vlachos, T., Arya, P., \& Miceli, P. (2017). Impact of high sulfur fuel and desulfation process on a close-coupled diesel oxidation catalyst and diesel particulate filter. Fuel, 198, 58-67.

[37] Kang, W., Choi, B., Jung, S., \& Park, S. (2018). PM and NOx reduction characteristics of LNT/DPF+ SCR/DPF hybrid system. Energy, 143, 439-447. 
[38] Bollerhoff, T., Markomanolakis, I., \& Koltsakis, G. (2012). Filtration and regeneration modeling for particulate filters with inhomogeneous wall structure. Catalysis today, 188(1), 24-31.

[39] Bensaid, S., Marchisio, D. L., \& Fino, D. (2010). Numerical simulation of soot filtration and combustion within diesel particulate filters. Chemical Engineering Science, 65(1), 357-363.

[40] Zhao, H., Ge, Y., Zhang, T., Zhang, J., Tan, J., \& Zhang, H. (2014). Unregulated emissions from diesel engine with particulate filter using Fe-based fuel borne catalyst. Journal of Environmental Sciences, 26(10), 2027-2033.

[41] Palma, V., Ciambelli, P., Meloni, E., \& Sin, A. (2015). Catalytic DPF microwave assisted active regeneration. Fuel, 140, 50-61.

[42] Stępień, Z., Ziemiański, L., Żak, G., Wojtasik, M., Jęczmionek, Ł., \& Burnus, Z. (2015). The evaluation of fuel borne catalyst (FBC's) for DPF regeneration. Fuel, 161, 278-286.

[43] P. Salvat, O. Marez and G. and Belot (2000), "Passenger Car Serial Application of a Particulate Filter System on a Common Rail Direct Injection Diesel Engine," SAE Technical Paper, no. 2000-01-0473, p. 15.

[44] Pérez, V. R., \& Bueno-López, A. (2015). Catalytic regeneration of diesel particulate filters: comparison of Pt and $\mathrm{CePr}$ active phases. Chemical Engineering Journal, 279, 79-85.

[45] Yamazaki, K., Sakakibara, Y., Daido, S., \& Okawara, S. (2016). Particulate matter oxidation over ash-deposited catalyzed diesel particulate filters. Topics in Catalysis, 59(10-12), 1076-1082.

[46 Corro, G., Cebada, S., Pal, U., Fierro, J. L. G., \& Alvarado, J. (2015). Hydrogen-reduced Cu/ZnO composite as efficient reusable catalyst for diesel particulate matter oxidation. Applied Catalysis B: Environmental, 165, 555-565.

[47] Palma, V., Ciambelli, P., \& Meloni, E. (2013). Catalyst load optimization for microwave susceptible catalysed DPF. CHEMICAL ENGINEERING, 32.

[48] He, C., Li, J., Ma, Z., Tan, J., \& Zhao, L. (2015). High NO2/NOx emissions downstream of the catalytic diesel particulate filter: An influencing factor study. Journal of Environmental Sciences, 35, 55-61.

[49] Ramdas, R., Nowicka, E., Jenkins, R., Sellick, D., Davies, C., \& Golunski, S. (2015). Using real particulate matter to evaluate combustion catalysts for direct regeneration of diesel soot filters. Applied Catalysis B: Environmental, 176, 436-443.

[50] Palma, V., \& Meloni, E. (2016). Microwave assisted regeneration of a catalytic diesel soot trap. Fuel, 181, 421429.

[51] Corro, G., Pal, U., Ayala, E., \& Vidal, E. (2013). Diesel soot oxidation over silver-loaded SiO2 catalysts. Catalysis today, 212, 63-69.

[52] Bai, S., Chen, G., Sun, Q., Wang, G., \& Li, G. X. (2017). Influence of active control strategies on exhaust thermal management for diesel particular filter active regeneration. Applied Thermal Engineering, 119, 297-303.

[53] Jiaqiang, E., Xie, L., Zuo, Q., \& Zhang, G. (2016). Effect analysis on regeneration speed of continuous regeneration-diesel particulate filter based on NO2-assisted regeneration. Atmospheric Pollution Research, 7(1), 917.

[54] Rodríguez-Fernández, J., Hernández, J. J., \& Sánchez-Valdepeñas, J. (2016). Effect of oxygenated and paraffinic alternative diesel fuels on soot reactivity and implications on DPF regeneration. Fuel, 185, 460-467.

[55] Dawei, Q., Jun, L., \& Yu, L. (2017). Research on particulate filter simulation and regeneration control strategy. Mechanical Systems and Signal Processing, 87, 214-226.

[56] Di Sarli, V., \& Di Benedetto, A. (2015). Modeling and simulation of soot combustion dynamics in a catalytic diesel particulate filter. Chemical Engineering Science, 137, 69-78.

[57] Bermúdez, V., Serrano, J. R., Piqueras, P., \& García-Afonso, O. (2015). Pre-DPF water injection technique for pressure drop control in loaded wall-flow diesel particulate filters. Applied Energy, 140, 234-245.

[58] V. Palma, E. Meloni, M. Caldera, D. Lipari, V. Pignatelli, and V. Gerardi (2016), "Catalytic wall flow filters for soot abatement from biomass boilers," Chemical Engineering. Transactions, vol. 50, pp. 253-258.

[59] Lupše, J., Campolo, M., \& Soldati, A. (2016). Modelling soot deposition and monolith regeneration for optimal design of automotive DPFs. Chemical Engineering Science, 151, 36-50.

[60] Ranji-Burachaloo, H., Masoomi-Godarzi, S., Khodadadi, A. A., \& Mortazavi, Y. (2016). Synergetic effects of plasma and metal oxide catalysts on diesel soot oxidation. Applied Catalysis B: Environmental, 182, 74-84.

[61] Tuler, F. E., Portela, R., Ávila, P., Bortolozzi, J. P., Miró, E. E., \& Milt, V. G. (2016). Development of sepiolite/SiC porous catalytic filters for diesel soot abatement. Microporous and Mesoporous Materials, 230, 11-19.

[62] Kim, H. J., Han, B., Hong, W. S., Shin, W. H., Cho, G. B., Lee, Y. K., \& Kim, Y. J. (2010). Development of electrostatic diesel particulate matter filtration systems combined with a metallic flow-through filter and electrostatic methods. International Journal of Automotive Technology, 11(4), 447-453.

[63] Graupner, K., Binner, J., Fox, N., Garner, C. P., Harry, J. E., Hoare, D., ... \& Williams, A. M. (2013). Pulsed Discharge Regeneration of Diesel Particulate Filters. Plasma Chemistry and Plasma Processing, 33(2), 467-477. 
[64] Palma, V., Ciambelli, P., Meloni, E., \& Sin, A. (2013). Study of the catalyst load for a microwave susceptible catalytic DPF. Catalysis today, 216, 185-193.

[65] V. Palma and E. Meloni (2016), "Microwave susceptible catalytic diesel particulate filter," Chemical Engineering Transaction, vol. 52, pp. 445-450.

[66] Terada, M., Kawamura, K., Kagomiya, I., Kakimoto, K. I., \& Ohsato, H. (2007). Effect of Ni substitution on the microwave dielectric properties of cordierite. Journal of the European Ceramic Society, 27(8-9), 3045-3048.

[67] Liu, Y., Luo, F., Su, J., Zhou, W., \& Zhu, D. (2015). Dielectric and microwave absorption properties of Ti3SiC2/cordierite composite ceramics oxidized at high temperature. Journal of Alloys and Compounds, 632, 623628.

[68] Hauck, H. S. (1970). Design considerations for microwave oven cavities. IEEE Transactions on Industry and General Applications, (1), 74-80.

[69] Feulner, M., Seufert, F., Müller, A., Hagen, G., \& Moos, R. (2017). Influencing Parameters on the MicrowaveBased Soot Load Determination of Diesel Particulate Filters. Topics in Catalysis, 60(3-5), 374-380.

[70] Zhang, B., Jiaqiang, E., Gong, J., Yuan, W., Zuo, W., Li, Y., \& Fu, J. (2016). Multidisciplinary design optimization of the diesel particulate filter in the composite regeneration process. Applied energy, 181, 14-28. 